\title{
Histochemical Assessment of Mucin-Secreting Cells from the Gastric Mucosa of Guinea Pigs
}

\author{
Adriana CHENDE ${ }^{1}$, Vasile RUS ${ }^{2}$, Cristian MARTONOS ${ }^{1 *}$, Dalma PIVARIU ${ }^{2}$, Aurel DAMIAN ${ }^{1}$, Viorel \\ MICLĂUȘ ${ }^{2}$, Adrian GAL ${ }^{2}$
}

\begin{abstract}
${ }^{1}$ Department of Anatomy, Faculty of Veterinary Medicine, University of Agricultural Sciences and Veterinary Medicine Cluj-Napoca, Calea Mănăştur 3-5, Cluj-Napoca, 400372, Romania

${ }^{2}$ Department of Cell Biology, Histology and Embryology, Faculty of Veterinary Medicine, University of

Agricultural Sciences and Veterinary Medicine Cluj-Napoca, Calea Mănăştur 3-5, Cluj-Napoca, 400372,

Romania

*Corresponding author: cristian.martonos@usamvcluj.ro
\end{abstract}

Bulletin UASVM Veterinary Medicine 77(2)/2020

Print ISSN 1843-5270; Electronic ISSN 1843-5378

doi:10.15835/buasvmcn-vm:2020.0032

\begin{abstract}
Stomach fragments from 3 guinea pigs were collected from the three regions: cardiac, fundic and pyloric, for histochemical investigations. The anatomical segments were processed by the classical method of inclusion in paraffin and the histological sections were stained with PAS reaction for highlighting the neutral mucins and the Alcian blue method for acid mucins. All the surface cells of the gastric mucosa and in the crypts were positive on the PAS reaction and negative in the case of the alcian blue reaction. This demonstrates that cells on the surface and in the crypts synthetize neutral mucins. In the case of the cardiac region glands, only a small number of cells were positive on the two histochemical reactions, which shows that the cardiac glands in guinea pig synthesize a very small amount of neutral and acidic mucins. There are no positive cells in neither reaction used in the fundic glands case, which shows that these glands do not synthesize mucins, neither neutral nor acidic content. The glands located in the pyloric region have cells in the deep half of the wall which were positive on both histochemical reactions, which shows that they synthesize both neutral mucins and acidic mucins.
\end{abstract}

Keywords: guinea pig, gastric glands

\section{Introduction}

The literature is quite extensive regarding the macroscopic aspects, in the case of Cavia porcellus. Thus, in the literature were reported a series of data on the anatomical aspects of the reproductive (Stan, 2015 (a)), digestive (Stan, 2018; Stan, 2014) and respirator system (Stan, 2015 (b)). Microscopic aspects in the case of the guinea pigs have been published regarding the structure of the esophagus (Rus et al. 2019), the tongue (Ciena et al. 2017), or the adrenal glands (Hassneen, 2014). In the mucosa of some cavitary organs of the digestive tract, there are cells that synthesize and eliminate in their lumen, substances that protect the mucosa and facilitate the progression of the food. These cells are present both in the surface epithelium of the gastrointestinal mucosa, in the walls of the glands, and secrete different types of mucins. To identify these mucins, the first time is to classify to a group of mucins (Bancroft and Stondard, 2013) and if desired, later, by appropriate techniques they can be differentiated between them structurally (Mureșan et al., 1976).

The mucins category occupies a special place among the secretions produced by the glandular cells existing in the components of the mucosa of the digestive tract. They play an important role in protecting the mucosa from physical or chemical 
aggression and also in lubricating the mucosal surface. The mucins produced by glandular cells are not all the same, they can be classified into several categories.

Mucin secretory cells are found in the epithelium lining the gastric mucosa and gastric crypts, in the gastro-duodenal glands, in the surface epithelium and in the glandular epithelium of the intestinal mucosa in all segments of the small and large intestine. For the proper functioning of the stomach, large amounts of mucins are needed, primarily for the protection of the mucosa from hydrochloric acid and digestive enzymes. The cells that line the gastric mucosa on the surface synthesize and secrete particular mucus, especially as a chemical structure of the mucus synthesized by the mucoid cells in the intestine. It should be noted that the secretion of cells from the gastric mucosa is continuous, unlike the goblet cells in the intestine whose secretion is discontinuous. Some authors claim that the mucus secreted by the cells lining the gastric mucosa also has a role in the mechanism of regulating the secretion of the gastric glands. (Adlersberg et al., 1955). The present study aims the histochemical assessment of mucin-secreting cells in the gastric mucosa, in the case of Cavia porcellus.

\section{Material and methods}

From three guinea pigs presented for histopathological diagnosis at the Histopathology Laboratory of the National Sanitary Veterinary and Food Safety Agency of Romania in Salaj, Zalau for diagnosis, stomach fragments were collected from the three regions: cardiac, fundic and pyloric. The harvested pieces were fixed in 10\% formalin for 7 days, then dehydrated with ethyl alcohol in increasing concentration $\left(70^{\circ}, 96^{\circ}\right.$ and absolute), clarified with 1-Butanol and included in paraffin. Sections with a thickness of 5 micrometers were cut and prepared for the histochemical highlighting of neutral and acidic mucins. The PAS reaction, first used in 1946 by McManus (Kiernan, 1999; Wulff Sonja, 2004, Layton and Brancoft, 2013) was first used to highlight neutral mucins. To highlight the acidic mucins, we used the Alcian blue staining at $\mathrm{pH} 2.5$, which highlights both unsulfated and sulfated mucins (Mureșan et al., 1976; Kiernan, 1999). The histochemical preparations obtained were examined under an Olimpus BX41 microscope, equipped with a digital camera for capturing images, model Olimpus E-330. The subsequent image processing was done using Adobe Photoshop 2020.

\section{Results and discussions}

The components of the guinea pigs gastric mucosa react different to the SCHIF reagent and Alcian blue, depending on the activity of each cell type, related to the anatomical region of the stomach in which they are located.

In the cardia region (Figure 1) there are differences in histochemical reactions in the

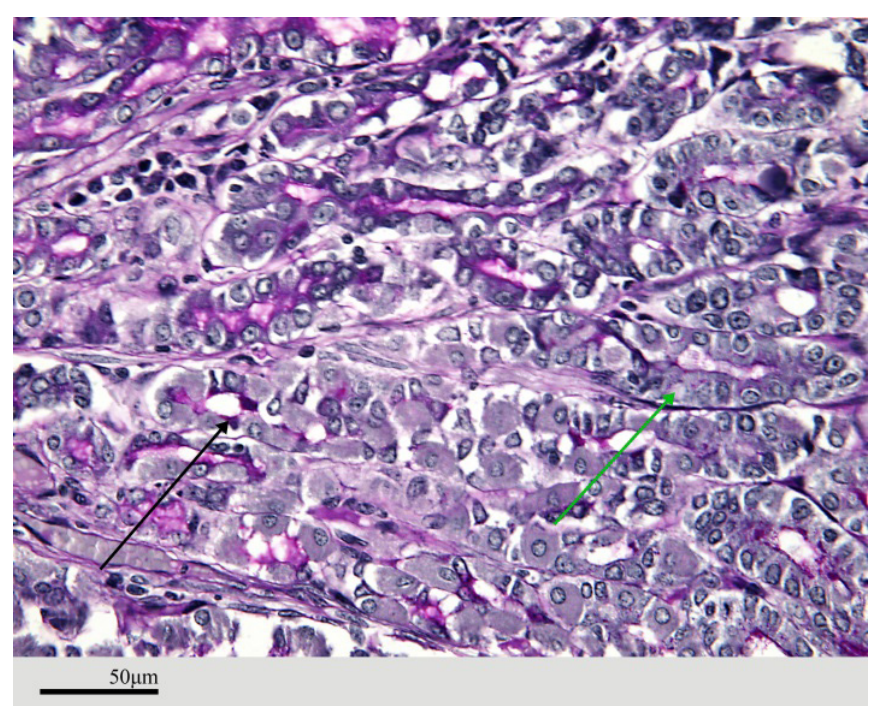

Figure 1. Guinea pig gastric mucosa-cardia region (PAS) Green arrow - cardiac glands with negative PAS cells; Black arrow - cardiac glands with positive PAS cells. 
case of the cells on the surface epithelium of the cardiac mucosa and those in the walls of the cardiac glands. Thus, the cells of the surface epithelium of the cardiac mucosa are intensely PAS+ in their apical half which suggests that they contain significant amounts of neutral mucins, which are concentrated in the apical half and stored for a period of time until they mature and are needed for to be removed by the apical pole at the surface of the mucosa. It should be noted that the gastric crypts in the cardia region, have the same behaviour compared to the SCHIF reagent, presenting intense PAS+ material in their apical half. If me make a quantitative assessment, we find some difference in this between the surface cells and those at the level of the crypts, in the sense that the surface cells contain larger amounts of PAS+ material. Regarding the cardiac glands, PAS+ material is found only very discreetly and only in some of them, which suggests that their secretion is not predominantly mucous, at least in terms of neutral mucins.

In the fundic region (Figure 3 ) the situation is somewhat similar to that in the cardia region, but there are also some differences. In this region, the cells on the surface of the gastric mucosa and those lining the crypts, are intensely PAS positive. The PAS+ material also occupies the apical half of the cells here and is relatively dense, with small differences between the cells on the surface and those in the crypts. From a quantitative point of view, the PAS+ material is higher than in the cardia region, which suggests that a larger amount of neutral mucus is produced here. The cells in the walls of the guinea pigs fundus glands are PAS negative.

In the piloric region (Figure 5) the situation is maintained with regard to the cells on the mucosal surface and those in the crypts, where the PAS reaction is intensely positive. If we compare with the cardia region, the degree of loading of the apical pole of the cells with PAS+ material is slightly lower. In this region, however, there are significant differences in the pyloric glands whose cells apear positive PAS in the deep half and negative PAS in the superficial half. The intensity of the PAS reaction is significant in the cells of the surface cells and in the crypts.

On the reaction with Alcian blue the general situation is different in the sense that the number of cells that synthesize acidic mucins is significantly lower that those that secrete neutal mucins.

In the cardia region (Figure 2), the cells lining the mucosa on the surface and in the crypts are negative to the reaction with Alcian blue, which suggests that they do not synthesize acidic mucins. At the level of the cardiac glands there is a positive Alcian blue reaction, but it is present only in a small number of cells and is of very discrete intensity. This suggests that some of the cells in the guinea pigs cardiac glands synthesize a very small amount of acidic mucins.

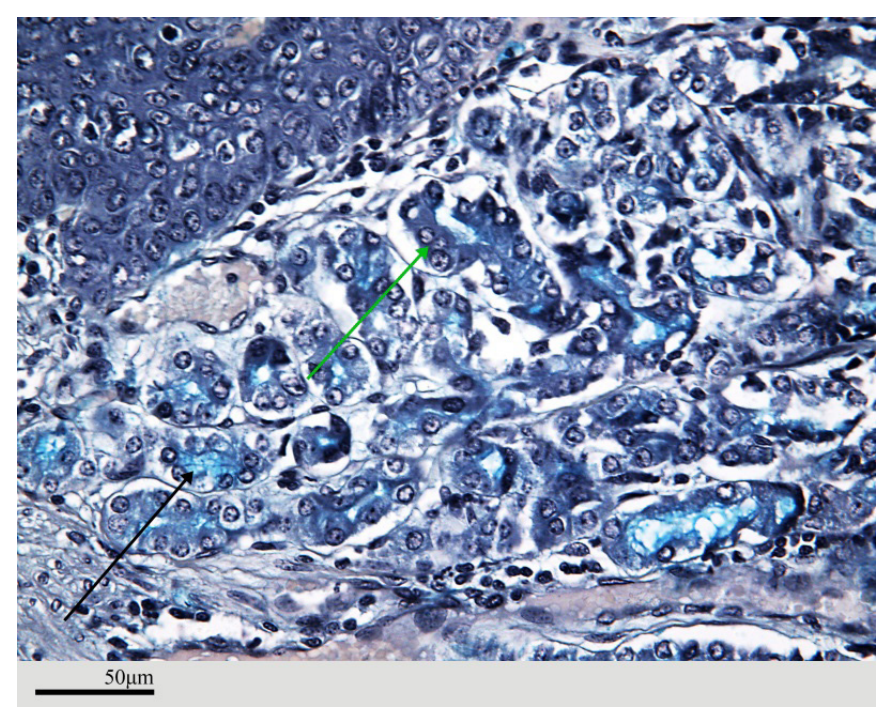

Figure 2. Guinea pig gastric mucosa-cardia region (AA) Green arrow - cardiac glands with negative alcian cells; Black arrow - cardiac glands with positive alcian cells. 
In the fundic region (Figure 4) the situation is negative in the case of Alcian blue reaction, of the cells lining the mucosa on the surface and in the crypts, which is not present in any cell, at any intensity. What is characteristic of this area is the fact that neither the cells in the fundic glands show a positive Alcian blue reaction, of any intensity. In conclusion the acidic mucins are not synthesized in the fundic region of the guinea pigs stomach.
In the pyloric region (Figure 6), the situation is maintained with regard to the cells lining the mucosa on the surface and in the crypts, where the reaction with Alcian blue is negative. A noteworthy difference is found in the pyloric glands, where the cells in their deep half show a positive Alcian reaction of medium intensity, which suggests that the glands in this region also synthesize not only neutral acidic mucins. Interestingly, the same cells that occupy the deep half of the glands synthesize

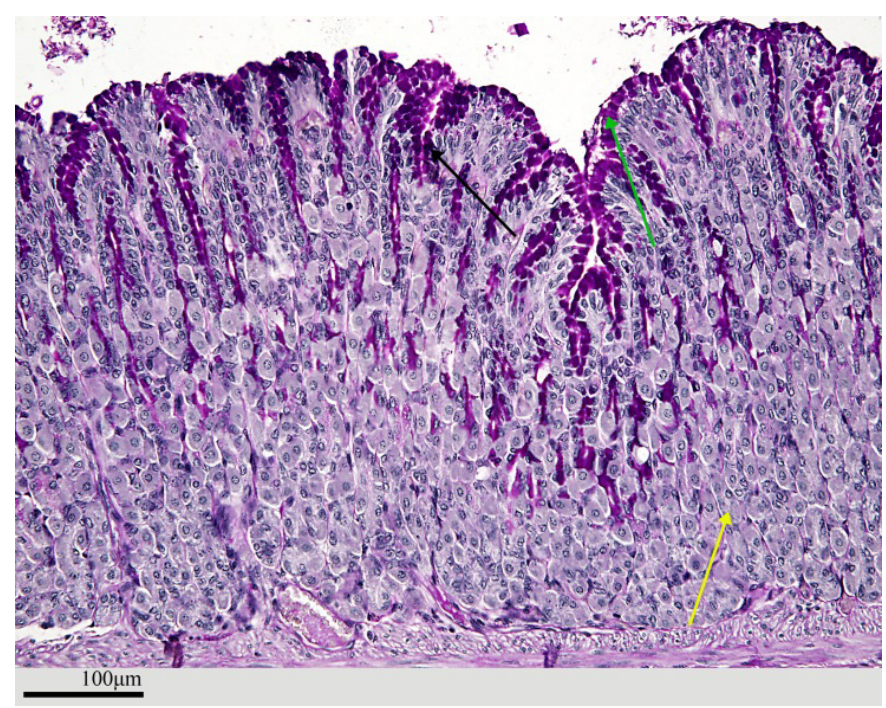

Figure 3. Gastric mucosa of guinea pigs-fundic region (PAS) Green arrow - surface epithelium with positive PAS cells; Black arrow - the epithelium in crypts with positive PAS cells; Yellow arrow - bottom glands with negative PAS cells.

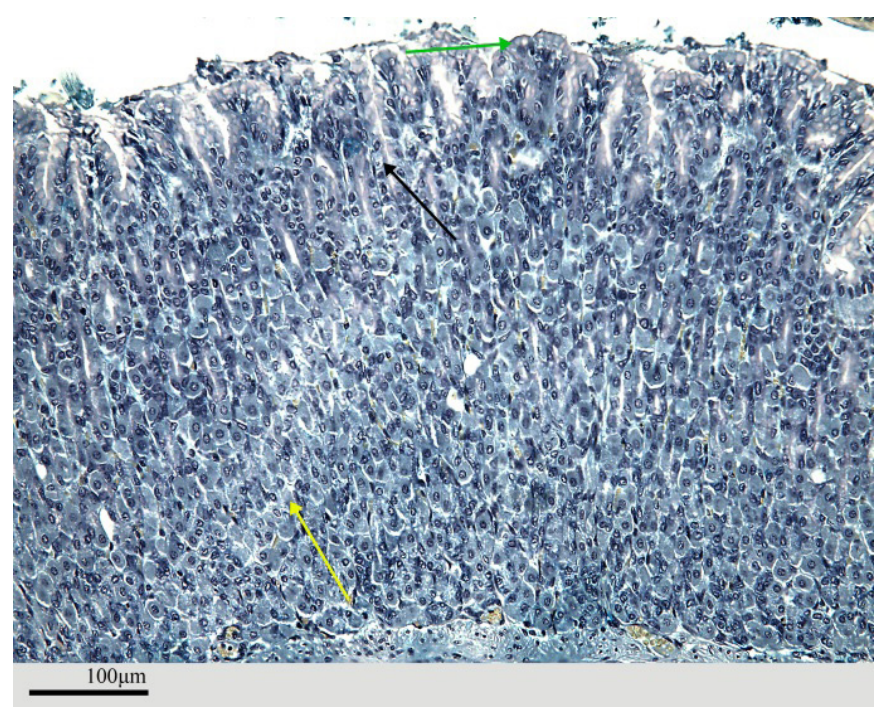

Figure 4. Guinea pig gastric mucosa-fundic region (AA) Green arrow - surface epithelium with negative alcian cells; Black arrow - the epithelium in crypts with negative alcian cells; Yellow arrow- fundic glands with negative alcian cells. 
both neutral mucins, which shows that these cells have intense and complex synthesis activity.

The guinea pig stomach mucosa contains structures that behave similarly to the corresponding structures from other species, but also some that differ more or less, either in one or both histochemical reactions used by us in this investigation. We could observe that there are components of the gastric mucosa present in all regions of the stomach, which have similar behavior in a certain histochemical reaction. We refer here first of all to the cells that line the gastric mucosa and that show intense PAS positive reaction in all three regions of the stomach. The positive PAS material is present only in the apical half of all epithelial cells lining the gastric mucosa, where it appears densely and intensely colored, this suggests that there are large amounts of neutral mucins here. This material stays here for a certain period of time, to mature and then to be removed

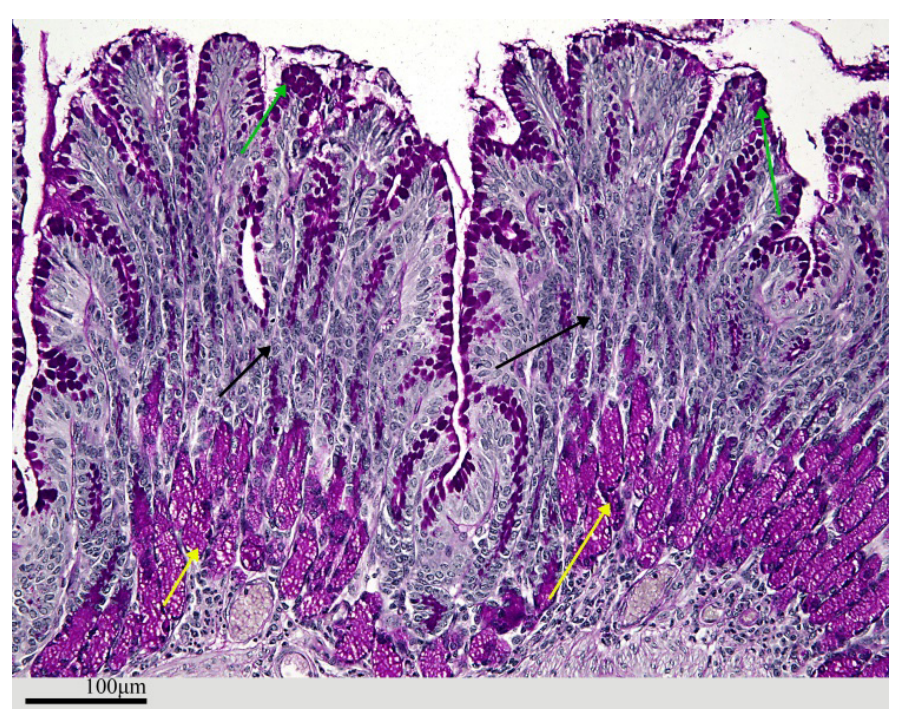

Figure 5. Gastric mucosa of guinea pigs pyloric region (PAS) Green arrow - surface epithelium with positive PAS cells; Black arrow - the upper half of the pyloric glands with negative PAS cells; Yellow arrow - the deep half of the pyloric glands with positive PAS cells.

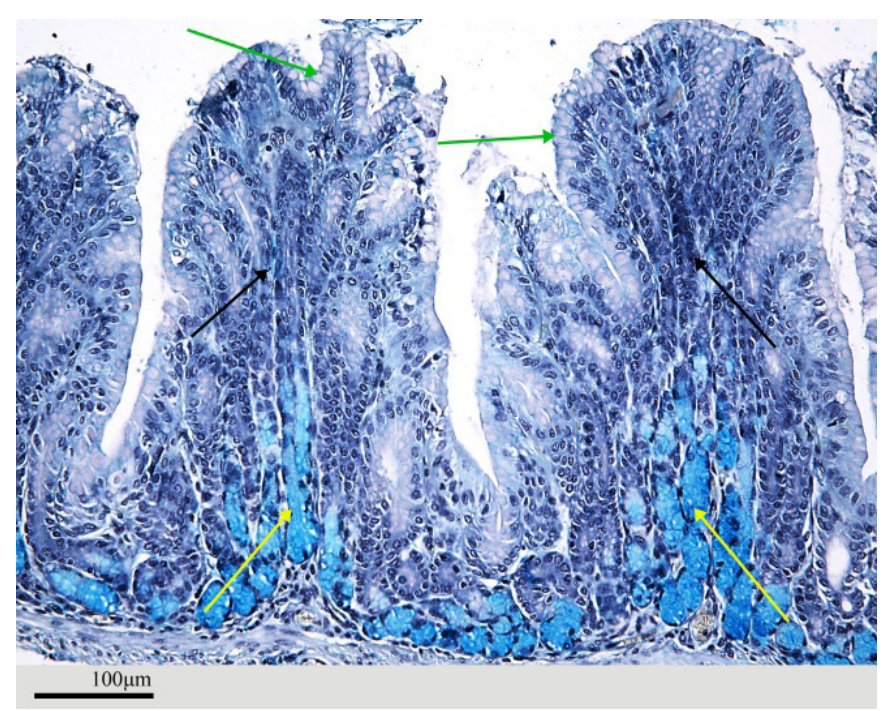

Figure 6. Gastric mucosa of guinea pigs-pyloric region (AA)

Green arrow - surface epithelium with negative alcian cells; Black arrow - the upper half of the pyloric glands with negative alcian cells; the deep half of the pyloric glands with positive Alcian cells. 
to the surface of the mucosa at the optimal time. As this mucus is vital for the protection of the mucosa from the action of hydrochloric acid and digestive enzymes, the cells of the surface epithelium of the gastric mucosa permanently produce large amounts of neutral mucus. The cells in all regions of the stomach have the lumen loaded with intense PAS positive mucus, with no differences in the intensity of the reaction, but there are still some differences in the degree of loading of the apical pole of cells in one region compared to others. The cells with the highest degree of neutral mucin loading are in the fundic region, where they occupy approximately the apical half of the cells. In the case of cells from the cardia and pyloric regions, the intensity of the reaction is comparable to that of the fundic region, but the mucus occupies about $30 \%$ of the cell here, with differences from one cell to another. The situation is somewhat comparable in the case of cells lining the gastric crypts and which also show an intense positive PAS reaction at the apical half.

We noticed the differences from one region to another in the case of cells in the crypts. The degree with mucus loading is the highest in the fundic region, while the intensity of the reaction is comparable in the three regions of the guinea pig stomach. If we compare the results obtained by us with the existing data in the literature, we find that they are similar, in the sense that the cells lining the gastric mucosa and the crypts synthesize neutral mucins in most species of mammals, including humans. (Raica et al., 2004).

Regarding the cells in the walls of the glands existing in the three regions of the stomach, the situation is particular in each region. We noticed differences both between regions and between the glands in the same region, or even between one part and another of the same gland.

The cardia region, in addition to being very small in guinea pigs, contains glands whose cells are mostly PAS negative and only in some glands there are cells with a positive PAS reaction of low to moderate intensity. They are arranged in groups and occupy only certain parts of the cardia region glands. These cells with a zonal arrangement only in some glands, are far from the majority. Given that the cells that show a positive PAS reaction are relatively few in the cardiac region and the intensity of the reaction is low to moderate, we can say that the glands in the cardiac region of the guinea pigs synthesize small to very small amounts of neutral mucins. The results obtained by us are not identical to those in the literature on the secretory activity of cardiac glands in other mammalian species, including humans, where these glands are made up of mucin-secreting cells. (Raica et al., 2004).

The fundic region of the guinea pigs stomach contains most of the glands, made up of negative PAS cells. In the case of these glands, there are no positive PAS cells, neither grouped nor even isolated, in any of them. This suggests that the fundus glands in the guinea pigs stomach do not synthesize neutral mucins, even in small amounts. The situation is similar with the datas existing in the literature on the activity of fundic glands in other mammalian species. (Raica et al., 2004).

The pyloric region of the guinea pigs stomach contains glands in which the PAS reaction is positive, but not in all the cells that form a gland. Thus, the cells which are positive at PAS reaction are grouped in the deep half of the glands, while those in the upper half are PAS negative. Regarding the intensity of the PAS reaction, it is relatively high, but not even at the level of the cells of the surface epithelium and the one that covers the gastric crypts in this region of the stomach. The appearance suggests that about half of the cells that form the pyloric glands in guinea pigs synthesize neutral mucins in relatively large quantities while the other half do not synthetize such material. The fact that the pyloric glands synthetize mucins has been reported in other species too, including humans (Raica et al., 2004), but without specifying what kind of mucin and whether it is all the cells that make up a gland or just a part of them, as we identified in guinea pig. According to other information in the literature, the pyloric glands are composed entirely of cells that secrete relatively large amounts of mucins in humans (Buligescu et al., 1982; RAICA et al., 2004) and larger in other mammalian species, like the goat, pig and the dog (Augley and Frye, 2001; Bacha and Bacha, 2006).

The reaction with Alcian blue also highlighted similar aspects, but also some different ones, from one region of the stomach to another, but also between the components from the same region. Similar aspects were highlighted regarding the lining epithelium of the gastric mucosa on the surface and in the crypts, where the reaction with 
Alcian blue was negative in all cells and in all regions of the stomach.Under these conditions we can say that the cells on the surface of the mucosa and in the crypts of the guinea pigs stomach do not synthesize acidic mucins. The results obtained by us are similar in this respect to those reported in other mammal species. Thus, some authors claim that the surface cells and in the crypts of the gastric mucosa synthesize large amounts of mucus intensely positive for the PAS reaction and negative for that with Alcian blue. (Raica et al., 2004).

Regarding the gastric glands, the situation is more diversified, with differences being reported from one region of the guinea pigs stomach to another. In the cardia region most cells in the cardiac glands are negative on reaction with Alcian blue and only some of them are positive. These cells occupy limited portions only in some glands, and their reaction with Alcian blue is weak, discrete. This shows that the glands in the cardia region of the guinea pigs stomach synthesize acidic mucins, but in very small quantities.

If we appreciate these glands in terms of mucin secretion, we can say that the guinea pigs synthesize both neutral mucins and acidic mucins, but in such small quantities that we can not say that they are glands with mucous secretion, as it is said to be in other mammal species. (Raica et al., 2004). Moreover, there are authors who claim that the secretion of these glands is represented in humans (Buligescu et al., 1982) and in some mammals (Bacha and Bacha, 2006) of neutral mucus.

In the fundic region, the glands appear to be composed entirely of negative Alcian cells. The negative results of the two histochemical reactions used by us, in the case of the fundic glands in guinea pigs, confirm that these glands are actively involved in the synthesis of other substances ((hydrochloric acid and pepsinogen) and not in the synthesis of mucins, neither neutral, nor acid. (Bacha and Bacha,2006).

In the pyloric region, the secretory activity of the glands is similar to the reaction with Alcian blue, with the situation existing in the case of the PAS reaction, in the sense that there are positive cells arranged in groups, in the deep half of the glands. The intensity of the reaction with Alcian blue is average in the cells of the pyloric glands of guinea pigs. Given that these cells occupy the deep half of the glands, we can say that the same cells synthesize both neutral mucins and acidic mucins.

If we make an overall assessment of the activity of mucin-secreting cells in the gastric mucosa of guinea pigs, we find that there are relatively large differences between the number of cells that secrete neutral mucus and those that secrete acidic mucus. Thus, neutral mucin-secreting cells are found in all regions of the stomach, in the structure of epithelia lining the mucosa on the surface and in crypts, but also in the walls of glands in some regions, primarily those in the pyloric region and to a lesser extent those in the cardia region.

Regarding the acidic mucins, the number of secretory cells is obviously lower and they are not present in all regions of the stomach. In the mucosa of the guinea pigs stomach we find such cells in the walls of the pyloric glands and in small numbers in the cardiac ones. Moreover, it is found that there are cells that synthesize only neutral mucins, but also cells that synthesize both categories of mucins. We highlighted these aspects in the cells in the deep half of the pyloric glands and it is possible but not very certain in some cells in the cardia region glands, which form a small and scattered groups, so that it is not possible to say precisely wheter they are the same cells or neighbouring cells.

Characteristic for the secretory activity of the gastric mucosa from guinea pigs is the fact that the glands in the cardia region synthetize very small amounts of muco-substances, and those in the pyloric region synthetize significant amounts of both neutral and acidic mucins. The particular aspects of the mucin-secreting activity in the guinea pigs stomach are certainly the result of the organ's adaptation to the specifics of the diet and the level of acidity of the gastric juice.

\section{Conclusion}

Cells lining the gastric mucosa and crypts in guinea pigs show an intense positive PAS reaction and a negative Alcian blue reaction in all three regions of the stomach, which shows that these cells synthetize neutral mucins but not acidic mucins.

The vast majority of cells in the cardiac glands are negative for both the PAS and Alcian blue reactions, and only a small number of cells are PAS positive and Alcian positive, which shows that the guinea pig cardiac glands synthetize very small amounts of neutral mucins and acid. 
The cells that form the fundic glands in the guinea pigs stomach are all negative to both the PAS and Alcian blue reactions, which shows that they do not synthesize mucins from the category of neutral or acidic ones, even in small quantities.

The cells in the deep half of the pyloric glands in the guinea pigs stomach were positive for both the PAS and Alcian blue reactions, demonstrating that the same cells synthesize both neutral and acidic mucins.

Given that neutral mucin-secreting cells are found in all regions of the stomach, and acidic mucin-secreting cells only in the pyloric glands and to a lesser extent in the cardiac glands, we can say that the mucous secretion of the stomach is mainly represented by neutral mucins.

Acknowledgments. This research did not receive any specific grant from funding agencies in the public, commercial, or not-for-profit sectors.

\section{References}

1. Aldersberg L, Brătianu S, Crișan C, Gundisch M, Paraschiv A, Niculescu IT, Rîmniceanu C, Țupa A (1955). Histologie, Vol II, Ed. Medicală, București.

2. Aughey E, Frye FL (2001). Comparative veterinary histology with clinical carrelates, Iowa State University Press.

3. Bacha WJ, Bacha LM (2006). Color Atlas of Veterinary Histology, Blackwell Publishing, Iowa, USA.

4. Bancroft JD, Stondard JH (2013). Classical histochemical methods, In: Suvarna SK, C Layton JD Bancroft, Bancroft's theory and practice of histological techniques, Seventh edition, Elsevier, Churchill Livingstone, pp. 567-567

5. Buligescu L, Gheorghescu B, Pușcaș I, Teodorescu Exarcu I(1982). Fiziologia și fiziopatologia digestiei, Ed. Medicală București, p. 132.

6. Ciena AP, Santos ACD, Vasconcelos BG, et al. (2017). Morphological characteristics of the papillae and lingual epithelium of guinea pig (Cavia porcellus). Acta Zool. 1-8. https://doi.org/10.1111/azo.12230.

7. Hassneen Ali. Al-Sharoot (2014). Histological Study of the Adrenal gland in Guinea Pig (Cavia porcellus),
International Journal of Advanced Research, Volume 2, Issue 9, 755-760.

8. Kiernan JA (1999). Histological and histochemical methods: Theory and practice, Ed. 3, Butterworth Heinemann, Oxford, UK, pp. 170-196

9. Layton C, Brancoft JD (2013). Carbohidrates, In: Suvarna S.K., C. Layton, J.D. Bancroft, Bancroft's theory and practice of histological techniques, Seventh edition, Elsevier, Churchill Livingstone, pp.221-240

10. Mureșan E, AT Bogdan, M Gaboreanu, AI Baba (1976). Tehnici de histochimie normală și patologică, Ed. Ceres, București, pp. 271

11. Raica M, O Mederle, ID Caruntu, A Pintea, AM Chindris (2004). Histologie teoretica si practica, Ed. Brumar, Timisoara,

12. Rus V, Ruxanda F, Damian A, Nuț C, Martonos C, Dogaru G, Miclăuș V, Gal AF (2019). Histological Aspects of the Esophagus in Guinea Pigs (Cavia Porcellus), Bulletin of University of Agricultural Sciences and Veterinary Medicine Cluj-Napoca. Veterinary Medicine, 76(2), p. 226231.

13. Stan F (2014). Comparative Morphological Study of Oral Cavity in Rabbits and Guinea Pigs, Scientific Works. Series C. Veterinary Medicine, Bucharest 60 (1), 27-32.

14. Stan F (2015a). Anatomical Particularities of Male Reproductive System of Guinea Pigs (Cavia porcellus), Bulletin UASVM Veterinary Medicine 72(2), p. 288-295.

15. Stan F (2015b). Comparative Anatomical Study of Lungs in Domestic Rabbits (Oryctolagus cuniculus) and Guinea Pigs (Cavia porcellus), Bulletin of University of Agricultural Sciences and Veterinary Medicine Cluj-Napoca. Veterinary Medicine, 75(1), p. 195196.

16. Stan F (2018). Comparative study of the liver anatomy in the rat, rabbit, guinea pig and chinchilla, Bulletin of University of Agricultural Sciences and Veterinary Medicine Cluj-Napoca. Veterinary Medicine, 70 (1), p. 3340.

17. Suvarna K, Layton C, Bancroft JD (2018). Bancroft's Theory and Practice of Histological Techniques 8th Edition, Elsevier

18. Wulff S (2004). Guide to special stains, DakoCytomation, USA, p. 24-44 